\title{
Effect of organic chemistry pedagogies with PEOE, VH, and discussion strategies on students' achievement in Ekiti State, Nigeria
}

\author{
Victor Oluwatosin Ajayi ${ }^{\mathrm{a}, 1, * ;}$ Emmanuel Edoja Achor ${ }^{\mathrm{b}, 2}$; Emmanuel Eriba Otor ${ }^{\mathrm{b}, 3}$ \\ a,b,c Benue State University, Makurdi, Nigeria \\ ${ }^{1}$ drvictorajayi@gmail.com *; ${ }^{2}$ nuelachor@yahoo.com; ${ }^{3}$ emmanueleribaotor@gmail.com \\ * corresponding author
}

\section{ARTICLE INFO}

Article history

Received 2020-04-29

Revised 2020-07-29

Accepted 2020-08-22

\section{Keywords}

Predict explain observe explain

Vee heuristic strategy

Discussion method

Students' achievement

Organic chemistry

\section{ABSTRACT}

The study investigated the effect of organic chemistry pedagogies with Predict Explain Observe Explain (PEOE), Vee Heuristic (VH), and discuss strategies on students' achievement. The study also investigated the interaction effect of treatments and gender on students' achievement in organic chemistry in Ekiti State, Nigeria. The instrument used for data collection was an organic chemistry achievement test (OCAT). KuderRichardson (KR-21) formula was used to test the internal consistency of OCAT, which yielded a reliability value of 0.94 . A sample of 308 students comprising 174 boys and 134 girls drawn from 9 schools within 9 Local Government Areas (LGA) out of 16 LGA in the Ekiti State, Nigeria, selected using multi-stage sampling techniques. Two research questions and two null hypotheses guided the study. The research questions were answered using Mean and Standard Deviation scores, while the null hypotheses were tested at 0.05 level of significance using Analysis of Covariance (ANCOVA). The study revealed that PEOE and VH strategies significantly improved students' achievement [F2, $307=255.284, \mathrm{P}<0.05]$ than the discussion strategy. It was also found that there was no significant interaction effect of treatments and gender on the mean achievement $[\mathrm{F} 2,307=.085, \mathrm{P}>0.050]$ of students in Organic Chemistry. It was recommended among others that since PEOE and VH strategies were found to be effective strategies for improving students' achievement in Organic Chemistry; Chemistry teacher's trainee should be trained on the use of PEOE and VH strategies and serving teachers should use it. The curriculum developers should use PEOE and VH strategies to develop and refine the Chemistry curriculum in general and Organic Chemistry in particular.

This is an open access article under the CC-BY-SA license.

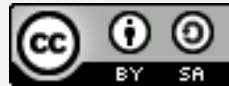

\section{Introduction}

Education is perceived as an instrument for achievement of national objectives [1], [2]. The government is well aware that the technological advancement and social-economic development are dependent on educational development. Science is the knowledge obtained from the systematic study of the structure and behaviour of the physical world, especially by observing, measuring and experimenting and the development of theories to describe the results of these activities [3]. Nations that are considered to be developed and largely considered as civilized have achieved that status through purposeful scientific education of their citizens. In cognizance with the importance of science and technology in Nigeria, Science subject such as Chemistry is taught in secondary schools to prepare a base for meaningful scientific and technological development [4]. 
Chemistry is an experimental science that systematically studies the composition, properties and activities of organic and inorganic substances and various elementary forms of matter [5]. Organic Chemistry which is the main focus of this study is the Chemistry of hydrocarbon and its derivatives. It has been found very useful in different fields of science and technology. It is utilized in petrochemical industries, beverage and alcohol processing production [6], [7]. Chemistry being a core science subject at the senior secondary school level of education is expected to serve as a base for scientific and technological knowledge that will enable the child to fit into the scientifically and technologically progressive society [8]. A good number of students who offer science and science related courses in higher institutions are expected to pass Chemistry at credit level and above [9], [10]. Despite this expectation, achievement of students offering Chemistry is poor. The poor achievement is attested to in the Chemistry result of students in Nigeria in the West African Senior Secondary School Certificate Examinations (WASSCE) May/June, 2009 to 2018 (see Appendix A). However, the West African Examination Council (WAEC) Chief Examiners' report (2017/2018) on Chemistry result indicates that students are weak in Organic Chemistry concept such as hydrocarbon, isomerism, alkanes, alkenes, alkynes, benzene, alkanols, alkanoic acids, alkanoates (esters), fat and oil, and classification of nomenclature of organic compound, due to the fact that candidates do not familiarize themselves with the required syllabus; teachers do not emphasize on areas of the syllabus where candidates appear to be weak such as Organic Chemistry; and teachers do not employ effective instructional methods (see Appendix B). The high rates of failure recorded by students in senior secondary schools in Nigeria have been a major concern to researchers in recent time. Consequently, the poor achievement in Chemistry in external examinations such as Senior Secondary Certificate Examination (SSCE) conducted by West Africa Examination Council (WAEC) and National Examination Council (NECO) and students' appears to have persisted which is often blamed on poor teaching methods. Poor strategy to teaching invariably translates to students' poor achievement.

Most Nigerian Chemistry teachers use discussion strategy most frequently in their Chemistry classrooms [11]. They present facts and principles contained in textbooks and students are rarely involved in any exercises. Based on this, the nation's quest for science and technological advancement will become a mirage, if effective modality is not put in place to incorporate innovative methods that promote meaningful learning and considering the importance of Chemistry in all round development, there is needs to make sure that Chemistry is properly taught most especially the difficult concepts such as Organic Chemistry using innovative strategies in order to enhance students' academic achievement. In the same vein, research reports advocates the use of self-learning strategies such as Predict-Explain-Observe-Explain (PEOE) and Vee Heuristic (VH) strategies, as a way of enhancing students' learning outcome.

Predict-Explain-Observe-Explain (PEOE) was modified from Predict-Observe-Explain (POE) [12], [13] to emphasize that the students need to explain their predictions to make their beliefs explicit [14]. Gernale presented a template of PEOE with a space for explanation of students' prediction. Students should know that their beliefs are important. PEOE is named to emphasize the importance of students' explanation [15]. Gernale explains that, PEOE is an instructional strategy where learner make predictions for an event and explain the reasons for his predictions, then conduct and observe a laboratory experiment and are required to compare his observations with his predictions in order to monitor his learning activities, thereby enhancing conceptual understanding of scientific knowledge. In this study, PEOE is used as an instructional strategy where two or more SSII students in a small group setting make predictions for an event and explain the reasons for their predictions, then conduct and observe a laboratory experiment and are required to compare their observations with their predictions, thereby enhancing conceptual understanding of scientific knowledge in Organic Chemistry.

A Vee heuristic diagram is a V-shaped diagram showing the relationships between conceptual or theoretical and methodological framework and the resultant knowledge or value claims of a concept. Vee Heuristic $(\mathrm{VH})$ strategy is the process of creating a $\mathrm{V}$-shaped diagram to represent key elements (ideas) that are contained in the structure of knowledge with two sides namely the theoretical or conceptual side (thinking side) on the left and methodological side (doing side) on the right in order to enhance conceptual understanding of scientific knowledge [16]. VH strategy is a tool that helps in seeing the interplay between what is known and what needs to be known or understood. In this study, VH strategy is an instructional strategy where two or more SSII students in a small group setting are engaged in coordinated and sustained efforts in the creation of a V-shaped diagram to represent key 
elements (ideas) that are contained in the structure of knowledge with two sides namely the theoretical (thinking side) on the left and methodological (doing side) on the right in order to monitor their learning activities and evaluate the results of these activities, thereby enhancing conceptual understanding of scientific knowledge in Organic Chemistry.

There are indications at all levels of education that females are grossly under-represented in terms of enrolment, participation and academic achievement in science, technology and mathematics which is often blamed on instructional and teacher qualities [17], [18]. Gender inequality in Chemistry has remained a perennial problem of global scope. Studies on gender differences in Chemistry achievement continued to yield inconsistent results and it has usually been attributed to unequal exposure of males and females to learning instructions relevant to Chemistry learning [19], [20]. Some studies indicate that boys achieve better either no difference or girls outperform boys have been demonstrated.Therefore, the study investigated if PEOE and VH strategies may be the instructional strategies that could close the gap among gender in Organic Chemistry. Thus, the study investigate the effect of organic chemisty pedagogies with Predict-Explain-Observe-Explain (PEOE), Vee Heuristic (VH) and discussion strategies on students' achievement [3].

The purpose of this study was to investigate the effect of organic chemisty pedagogies with PredictExplain-Observe-Explain (PEOE), Vee Heuristic (VH) and discussion strategies on students' achievement in Ekiti State, Nigeria. Specifically, the study:First, determine the effects of PEOE strategy, VH strategy and discussion strategy on students' achievement in Organic Chemistry. Second, ascertain the interaction effect of treatments and gender on students' achievement in Organic Chemistry. The following research questions guided the study: (1) What are the mean achievement scores differences among students taught Organic Chemistry using PEOE strategy, VH strategy and discussion strategy? (2) What is the mean interaction effect of treatments and gender on students' achievement in Organic Chemistry? The following null hypotheses were tested: first, there is no significant difference in the mean achievement scores of students taught Organic Chemistry using Predict-Explain-Observe-Explain (PEOE) strategy, Vee heuristic (VH) strategy and discussion strategy. Second, there is no significant interaction effect of treatments and gender on the mean achievement scores of students in Organic Chemistry.

\section{Method}

The study adopted a quasi-experimental non-randomized pre-test, post-test control group design. This design was adopted because it is not possible to have complete randomization of the subject as this may disrupt school organization. The study area was Ekiti State, Nigeria. The target population of this study was 14,753 which was the population of SSII chemistry students in study area. A sample of 308 students comprising 174 boys and 134 girls drawn from 9 schools within 9 Local Government Areas (LGA) out of 16 LGA in the Ekiti State, Nigeria selected using multi-stage sampling techniques. An instrument known as Organic Chemistry Achievement Test (OCAT) was used for data collection. OCAT was adopted from West African Examination Council (WAEC) past examination question papers of 2002-2017. OCAT items were based on WAEC, which is standardized, since the target of the study was to enhance the students' achievement, at this level. The test instrument consists two sections. Section A consists bio-data information of the respondents, while section B consists 40 structured multiple choice objective items with four options (A, B, C, D) drawn from the concepts of organic chemistry to which respondents are expected to provide the correct answers by selecting the correct option.

However, standardized tests do have environmental, regional and sociological sensitivity the items were face validated by presenting them to three experts in Science Education and one lecturer that is knowledgeable in test and measurement in the Department of Curriculum and Teaching, Benue State University, Makurdi and one expert in test and measurement in the College of Agricultural and Science Education, Department of Educational Foundations and General Studies, Federal University of Agriculture, Makurdi. The experts were asked to assess the instrument in terms of scope of coverage, content relevance, ambiguity, and vagueness of expression. Corrections and suggestions arising from these experts were used to review the instrument and the instructional packages. Organic Chemistry Achievement Test (OCAT) upon validation was trial-tested to establish the reliability of the instrument. Kuder-Richardson (KR-21) formula was used to test internal consistency of OCAT which gave reliability value of 0.94 . 
Fig 1 explain the schematic design. Before the commencement of the actual treatment, the researcher used one week for the training of the Chemistry teachers who served as research assistants. Intact classes were assigned to experimental and control groups after which Organic Chemistry Achievement Test (OCAT) was administered as pre-test by the researcher with the assistance of the sampled schools Chemistry teachers. This lasted for one week before actual teaching commences. During lessons, the teachers taught the experimental group one and experimental group two Organic Chemistry topics using predict-explain-observe-explain and Vee heuristic instructional strategy respectively in line with lessons procedure prepared by the researcher. The control group were also taught the same Organic Chemistry topics using the discussion lesson plans. This lasted for six weeks. At the end of these actual teaching periods, the pre-OCAT was reshuffled and administered as posttest which lasted for one week and the post test was marked by the research assistants using the marking scheme developed by the researcher. The pre-test score constituted the covariant of the posttest scores. Mean and Standard Deviation scores were used to answer the research questions while Analysis of Covariance (ANCOVA) was used to test the null hypotheses.

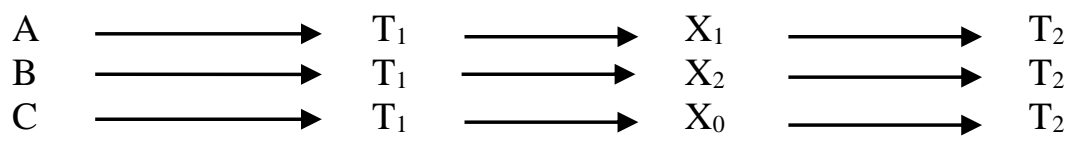

Fig. 1. Schematic design of the Study

Explanation:

$\mathrm{A}=$ Experimental group 1.

$\mathrm{B}=$ Experimental group 2 .

$\mathrm{C}=$ Control group.

$\mathrm{T}_{1}=$ Administration of Pre-OCAT

$\mathrm{T}_{2}=$ Administration of Post-OCAT.

$\mathrm{X}_{1}=$ Administration of first treatment (Predict-Explain-Observe-Explain Strategy).

$\mathrm{X}_{2}=$ Administration of second treatment (Vee Heuristic Strategy).

$\mathrm{X}_{0}=$ Absence of any treatment and use of Discussion strategy.

\section{Results and Discussion}

Presentations in this section are based on research questions and null hypotheses

\subsection{Research Question One}

What are the mean achievement scores differences among students taught Organic Chemistry using PEOE strategy, VH strategy and discussion strategy? The answer to research question one is contained on Table 1.

Table 1. Mean Achievement and Standard Deviation Scores of Students taught Organic Chemistry using PEOE strategy, VH strategy and discussion strategy

\begin{tabular}{|c|c|c|c|c|c|c|}
\hline \multirow{2}{*}{ Group } & \multirow[t]{2}{*}{$\mathbf{N}$} & \multicolumn{2}{|c|}{ PRE- OCAT } & \multicolumn{2}{|c|}{ POST-OCAT } & \multirow{2}{*}{ Mean Gain within Group } \\
\hline & & $\tilde{x}$ & $\delta$ & $\tilde{x}$ & $\delta$ & \\
\hline PEOE strategy & 104 & 10.17 & 3.23 & 29.32 & 5.37 & 19.15 \\
\hline Discussion & 103 & 10.15 & 3.10 & 15.56 & 3.93 & 5.41 \\
\hline Mean diff. between Groups & & 0.02 & & 13.76 & & 13.74 \\
\hline VH strategy & 101 & 10.16 & 3.22 & 27.91 & 5.14 & 17.75 \\
\hline Discussion & 103 & 10.15 & 3.10 & 15.56 & 3.93 & 5.41 \\
\hline Mean diff. between Groups & & 0.01 & & 12.35 & & 12.34 \\
\hline PEOE strategy & 104 & 10.17 & 3.23 & 29.32 & 5.37 & 19.15 \\
\hline VH strategy & 101 & 10.16 & 3.22 & 27.91 & 5.14 & 17.75 \\
\hline Mean diff. between Groups & & 0.01 & & 1.41 & & 1.40 \\
\hline
\end{tabular}

\subsection{Research Question Two}

What is the mean interaction effect of treatments and gender on students' achievement in Organic Chemistry? The answer to research question two is contained on Fig 2. 


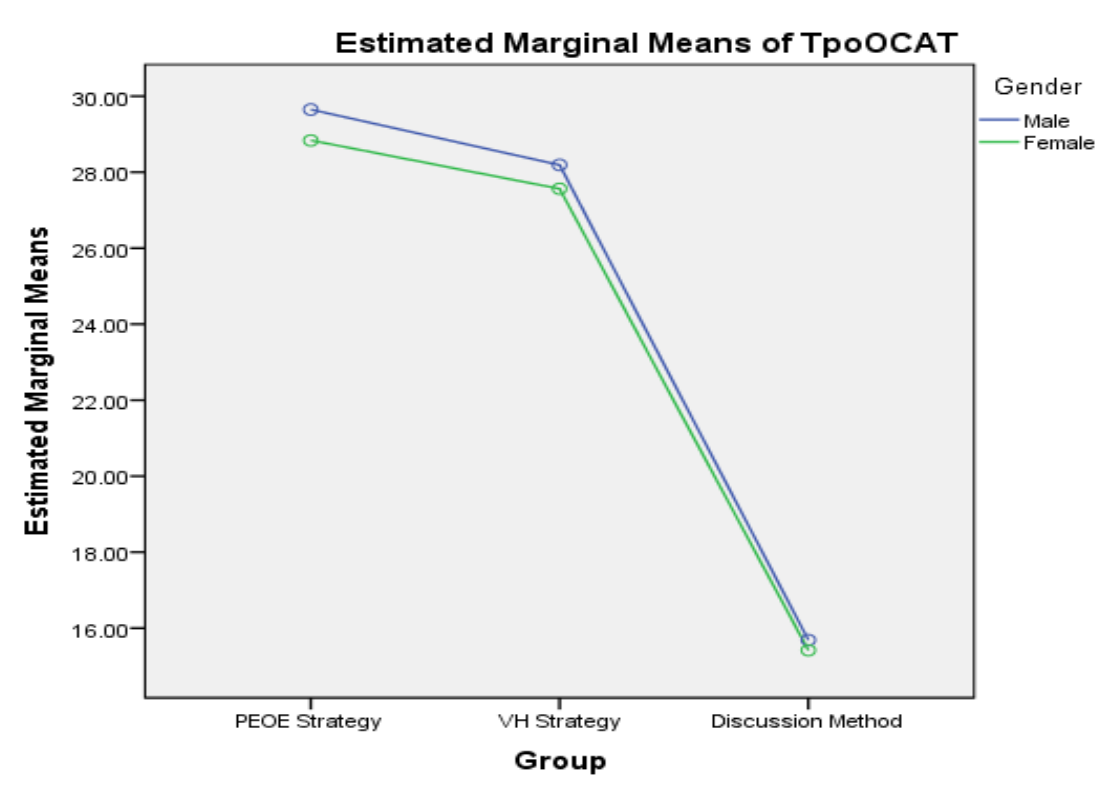

Covariates appearing in the model are evaluated at the following values: TprOCAT $=10.1591$

Fig. 2. Interaction plot of treatments and gender on students' achievement in Organic Chemistry

Fig 2 presents a graph of the interaction of treatments and gender on the mean achievement scores of students in Organic Chemistry. The graph lines for gender did not intercept which suggests that interactive effect of treatments and gender on students' achievement in Organic Chemistry was very minimal.

\subsection{Hypothesis One}

There is no significant difference in the mean achievement scores of students taught Organic Chemistry using Predict-Explain-Observe-Explain (PEOE) strategy, Vee heuristic (VH) strategy and discussion strategy. The analysis of hypothesis one is contained on Table 2.

Table 2. Two-Way ANCOVA for Mean Achievement Scores of Students taught Organic Chemistry using PEOE Strategy, VH Strategy and Discussion Strategy

\begin{tabular}{lcccccc}
\hline \multicolumn{1}{c}{ Source } & $\begin{array}{c}\text { Type III sum of } \\
\text { squares }\end{array}$ & $\boldsymbol{d f}$ & $\begin{array}{c}\text { Mean } \\
\text { Square }\end{array}$ & F & Sig. & $\begin{array}{c}\text { Partial Eta } \\
\text { Squared }\end{array}$ \\
\hline Corrected model & $12185.784^{\mathrm{a}}$ & 5 & 2030.964 & 89.967 & 0.000 & 0.642 \\
Intercept & 11702.639 & 1 & 11702.639 & 518.399 & 0.000 & 0.633 \\
TPrOCAT & 346.379 & 1 & 346.379 & 15.344 & 0.000 & 0.049 \\
Group & 11525.883 & 2 & 5762.942 & 255.284 & 0.000 & 0.629 \\
Group*Gender & 3.817 & 2 & 1.909 & 0.085 & 0.919 & 0.001 \\
Error & 6794.953 & 301 & 22.575 & & & \\
Total & 200201.000 & 308 & & & & Source: Field Survey, 2019 \\
Corrected Total & $18980.737 \quad$ b. R squared = .642 (Adjusted R Squared= .635)
\end{tabular}

Table 2 presents the two-way ANCOVA result for mean achievement scores of students taught Organic Chemistry using Predict-Explain-Observe-Explain (PEOE) strategy, Vee Heuristic (VH) strategy and discussion strategy (DS). The data in table 2 reveal that the observed mean difference in the achievement scores among the groups was significant $\left[\mathrm{F}_{2,307}=255.284, \mathrm{P}<0.05\right]$. Hence, the null hypothesis that there is no significant difference in the mean achievement scores of students taught Organic Chemistry using PEOE strategy, VH strategy and DS was rejected. This implies that there is a significant difference in the mean achievement scores among the groups. Meanwhile, the effect size was 0.629 as indicated by the corresponding partial eta squared value which [15] considered as large effect size. This implies that, $62.9 \%$ of the difference or variance in the achievement scores among 
the groups was explained by the treatments. Hence, the difference in the achievement scores among the groups has a large statistical effect size.

Table 3. Bonferroni Post Hoc Comparison for Mean Achievement Scores of Students' taught Organic Chemistry using PEOE, VH and DS

\begin{tabular}{ccccc}
\hline (I) & (J) & Mean Difference (I-J) & Std. Error & Sign. \\
Group & Group & $13.689^{*}$ & 0.667 & 0.000 \\
PEOE & DS & $12.324^{*}$ & 0.669 & 0.000 \\
VH & DS & -1.365 & 0.671 & 0.128 \\
VH & PEOE & & \multicolumn{2}{c}{ c. Source: Field Survey, 2019 }
\end{tabular}

Table 3 shows Bonferroni post-hoc comparison for mean achievement scores of students' taught Organic Chemistry using Predict-Explain-Observe-Explain (PEOE) strategy, Vee Heuristic (VH) strategy and discussion strategy (DS). The results reveal that the mean difference (I-J) between PEOE and DS is $13.689 *$ and this is significant at $\mathrm{p}<0.05$. This implies that there is a significant difference in the mean achievement scores between the students taught Organic Chemistry using PEOE and those taught using DS in favour of PEOE. Likewise, the results reveal that the mean difference (I-J) between $\mathrm{VH}$ and DS is $12.324^{*}$ and this is significant at $\mathrm{p}<0.05$. This implies that there is a significant difference in the mean achievement scores between the students taught Organic Chemistry using VH and those taught using DS in favour of VH. However, the paired comparison of VH and PEOE showed a mean difference of -1.365 and this is not significant at $p>0.05$. This indicates no significant difference in the mean achievement scores between students taught using PEOE and VH strategies.

\subsection{Hypothesis Two}

There is no significant interaction effect of treatments and gender on the mean achievement scores of students in Organic Chemistry. The data analysis of table 2 is used to explain hypothesis 2 . Table 2 also presents the interaction effect of instructional strategies and gender. The data in Table reveals that there is no significant interaction effect of treatments and gender on the mean achievement scores of students in Organic Chemistry [F2, $307=.085, \mathrm{P}>0.050]$. The null hypothesis is therefore not rejected. Meanwhile, the effect size was 0.001 as indicated by the corresponding partial eta squared value which [17] considered as small effect size. This implies that, only $0.1 \%$ of the interaction in the achievement scores among groups was explained by treatments and gender. Hence, the interaction of treatments and gender on students' achievement has small statistical effect size. The main focus of this study was to investigate the effect of organic chemistry pedagogies with Predict-Explain-ObserveExplain (PEOE), Vee Heuristic (VH) and discussion strategies on students' achievement in Ekiti State, Nigeria. The findings of this study revealed that students taught Organic Chemistry using predictexplain-observe-explain (PEOE) Strategy achieved significantly higher than their counterparts taught using discussion strategy. This is in line with findings that students improved significantly in their achievement in Science and Elementary Basic Science respectively when taught using PEOE strategy compared to those taught using conventional teaching method [8], [11]. In another related study, investigated the effect of predict-observe-explain (POE) on the understandings of grade II chemistry students about gases [10]. Though the strategy used did not emphasize the important of students' explanation for their prediction. Yet, the finding of study revealed that, POE significantly enhanced students' understandings than traditional teaching method.

The likely explanation for this outcome may be connected to the fact that the Predict-ExplainObserve-Explain (PEOE) strategy helped the learners to possess a meaningful in-depth knowledge of the content area by finding out their initial ideas and motivating them to want to explore the concept and generate investigation when compared to the discussion strategy. PEOE strategy helps students to learn meaningfully because it focuses on linking students existing ideas and beliefs relevant to a situation and exploring the appropriateness of these ideas and beliefs. Therefore, if PEOE strategy is implemented in classroom, it will enhance the teaching and learning of Chemistry in general and Organic Chemistry in particular, thereby improving students' achievement in Chemistry in external examinations. It was also found that students exposed to Vee Heuristic (VH) strategy achieved significantly higher than those taught using discussion method. This finding agrees with found that students using VH strategy had higher achievement than those taught using traditional teaching method [15]. Similarly, this is in line with findings that students improved significantly in their 
achievement in Physics and Biology respectively when taught using VH strategy compared to those taught using lecture method [16].

The likely explanation for this outcome may also be connected to the fact that the use of Vee Heuristic $(\mathrm{VH})$ strategy provides a format for students to construct their knowledge about a concept. Students can see how scientific knowledge is developed through the process of reflecting on what they know and the investigation they undertake. Unlike, when compared to discussion method that only promotes passive learning. Therefore, Using VH strategy will make students begin to appreciate practical chemistry as Vee diagram generated can be used in place of any laboratory report. Therefore, if VH strategy is implemented in classroom, it will enable students to understand how concepts and processes are meaningfully learn because its purpose is to interplay between what is familiar and what they has yet to be known or understood in Chemistry in general and Organic Chemistry in particular.

The study revealed that students exposed to Predict-Explain-Observe-Explain (PEOE) achieved slightly higher than their counterparts using Vee Heuristic (VH) strategy but ANCOVA test shows that the difference was no significant. This implies that, the difference in the achievement of students taught Organic Chemistry using PEOE and VH strategies was not significant. There was a scarcity of studies on comparison between PEOE and VH strategies on students' achievement in science subjects before. However, the likely explanation for this outcome may be attributed to the fact that both PEOE and $\mathrm{VH}$ strategies are used to help students develop a cognitive structure that enable meaningful learning. The instructional strategies enable students to understand the structure of knowledge and process of knowledge construction. Thus, if either PEOE or VH strategy is implemented in classroom, it will enhance the teaching and learning of Chemistry in general and Organic Chemistry in particular. The finding of this study revealed that there is no significant interaction between strategies and gender on mean achievement scores of students in Organic Chemistry. This implies that either PredictExplain-Observe-Explain (PEOE) or Vee Heuristic (VH) strategy is superior to the discussion method irrespective of gender in fostering students' achievement. Treatment interaction generally implies that different learners with different characteristics may profit more from one type of instructional method than from another and that therefore it may be possible to find the best match of learners' characteristic and instructional method in other to maximize learning outcomes. In this case, there is no need for separation of instructional method for male and female since either PEOE or VH strategy could be used successfully for the three groups.

\section{Conclusion}

It is evident from the findings of this study that the use of both Predict-Explain-Observe-Explain (PEOE) strategy and Vee heuristic (VH) strategy enhanced students' achievement in Organic chemistry than the use of discussion strategy. There was no interaction effect between treatments and gender on students' achievement in Organic Chemistry. This implies that there is no need for separation of instructional strategy for male and female since either PEOE strategy or VH strategy could be used successfully. We have recommendations in this study, first, Chemistry teacher's trainee should be train on the application of Predict-Explain-Observe Explain (PEOE) strategy and Vee heuristic ( $\mathrm{VH})$ strategy and serving teachers should employ the use of PEOE and $\mathrm{VH}$ strategies in teaching to enhance students' achievement in Organic Chemistry. second, the curriculum developers should use PEOE and VH strategies to develop and refine the Chemistry curriculum in general and Organic Chemistry in particular. Third, ministry of Education, school administrators and professional bodies such as Association of Science Educators (ASE) and Science Teachers Association of Nigeria (STAN) should organize conferences or seminars and workshops to popularize and sensitize chemistry teachers on the integration of PEOE and $\mathrm{VH}$ instructional strategies in teaching Organic Chemistry.

\section{References}

[1] R. I. Osarenren-Osaghae and Q. O. Irabor, "Educational Policies and Programmes Implementations: A Case Study of Education Funding, Universal Basic Education (UBE) and Teacher Education.," Int. J. Educ. Adm. Policy Stud., vol. 10, no. 8, pp. 91-102, 2018, available at: Eric.ed.gov.

[2] FEDERAL REPUBLIC OF NIGER, NATIONAL POLICY ON EDUCATION. Nigeria: Nigerian Educational Research and Development Council (NERDC), 2004, available at: wbgfiles.worldbank.org. 
[3] V. O. Ajayi, "Effects of Predict-Explain-Observe-Explain and Vee Heuristic Strategies on Students' Achievement, Metacognitive Awareness and Self-Efficacy Belief in Organic Chemistry in Ekiti State, Nigeria," Metacognitive Aware. Self-Efficacy Belief Org. Chem. Ekiti State, Niger. (December 17, 2019), 2019, available at: Google Scholar.

[4] G. Demircioğlu, H. Demircioğlu, and A. Aslan, "THE EFFECT OF PREDICT-OBSERVE-EXPLAIN TECHNIQUE ON THE UNDERSTANDINGS OF GRADE 11 STUDENTS ABOUT THE GASES.," $J$. Educ. Instr. Stud. World, vol. 7, no. 4, 2017, available at: Google Scholar.

[5] F. Senese, "Introduction to chemistry," Retrieved 13th July, 2016, available at: Google Scholar.

[6] C. Y. Ling, S. Osman, M. F. Daud, and W. N. W. Hussin, "Application of Vee Diagram as a ProblemSolving Strategy in Developing Students' Conceptual a nd Procedural Knowledge," Int. J. Innov. Technol. Explor. Eng., vol. 8, no. 10, pp. 2796-2800, 2019, doi: 10.35940/ijitee.J9591.0881019.

[7] D. K. Mutai, "Effects of gowin's vee heuristic teaching strategy on secondary school students' conceptual understanding and metacognition in the topic of moments in physics, in Uasin Gishu County, Kenya." Egerton University, 2015, doi: 41.89.96.81:8080/xmlui/handle/123456789/1511.

[8] V. O. Ajayi and J. Ogbeba, "Effect of Hands-on Activities on Achievement and Retention of Senior Secondary Chemistry Students in Stoichiometry," 2017, doi: 2990679.

[9] W. Tyson, R. Lee, K. M. Borman, and M. A. Hanson, "Science, technology, engineering, and mathematics (STEM) pathways: High school science and math coursework and postsecondary degree attainment," J. Educ. Students placed risk, vol. 12, no. 3, pp. 243-270, 2007, doi: 10.1080/10824660701601266.

[10] P. M. Sadler and R. H. Tai, "Advanced placement exam scores as a predictor of performance in introductory college biology, chemistry and physics courses.," Sci. Educ., vol. 16, no. 2, pp. 1-19, 2007, available at: Eric.ed.gov.

[11] D. Oludipe and J. O. Awokoy, "Effect of cooperative learning teaching strategy on the reduction of students' anxiety for learning chemistry," J. Turkish Sci. Educ., vol. 7, no. 1, pp. 30-36, 2010, available at: Google Scholar.

[12] P. A. Bajar-Sales, R. A. Avilla, and V. M. I. Camacho, "PREDICT-EXPLAIN-OBSERVE-EXPLAIN (PEOE) APPROACH: TOOL IN RELATING METACOGNITION TO ACHIEVEMENT IN CHEMISTRY," Electron. J. Res. Sci. Math. Educ., vol. 19, no. 7, 2015, available at: Google Scholar.

[13] P. Phanphech, T. Tanitteerapan, and E. Murphy, "Explaining and enacting for conceptual understanding in secondary school physics," Issues Educ. Res., vol. 29, no. 1, pp. 180-204, 2019, available at: Google Scholar.

[14] B. Coştu, A. Ayas, and M. Niaz, "Investigating the effectiveness of a POE-based teaching activity on students' understanding of condensation," Instr. Sci., vol. 40, no. 1, pp. 47-67, Jan. 2012, doi: 10.1007/s11251-011-9169-2.

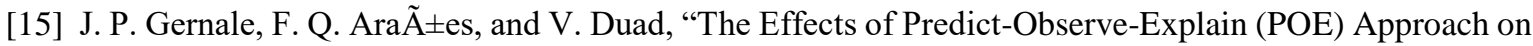
Studentsâ $€^{\mathrm{TM}}$ Achievement and Attitudes Towards Science,” Norm. Light., vol. 9, no. 2, 2015, available at: Google Scholar.

[16] D. B. Gowin, “The domain of education," Manuscr. Doc., 1977, available at: Google Scholar.

[17] L. Cuban, Teachers and machines: The classroom use of technology since 1920. Teachers College Press, 1986, available at: Google Scholar.

[18] M. T. Brownell, A. Adams, P. Sindelar, N. Waldron, and S. Vanhover, "Learning from collaboration: The role of teacher qualities," Except. Child., vol. 72, no. 2, pp. 169-185, 2006, doi: $10.1177 / 001440290607200203$.

[19] R. C. Turner and H. A. Lindsay, "Gender differences in cognitive and noncognitive factors related to achievement in organic chemistry," J. Chem. Educ., vol. 80, no. 5, p. 563, 2003, available at: Google Scholar.

[20] A. Ziegler* and H. Stoeger, "Evaluation of an attributional retraining (modeling technique) to reduce gender differences in chemistry instruction," High Abil. Stud., vol. 15, no. 1, pp. 63-83, 2004, doi: $10.1080 / 1359813042000225348$. 


\section{Appendix A}

Analysis of chemistry students' achievement in wassce in Nigeria (may/june 2009-2018

\begin{tabular}{cccccccc}
\hline Year & No. Registered & \multicolumn{2}{c}{ A1 to C6 } & \multicolumn{2}{c}{ D7 to E8 } & \multicolumn{2}{c}{ Failure (F9) } \\
& & Total & \% & Total & \% & Total & \% \\
\hline 2018 & 894,748 & 359,546 & 40.18 & 286,124 & 31.98 & 249,078 & 27.84 \\
2017 & 846,232 & 331,977 & 39.23 & 241,168 & 28.50 & 273,087 & 32.27 \\
2016 & 819,469 & 325,735 & 39.75 & 257,328 & 31.40 & 236,406 & 28.85 \\
2015 & 758,849 & 293,522 & 38.68 & 263,809 & 34.76 & 201,518 & 26.56 \\
2014 & 719,425 & 289,784 & 40.28 & 239,990 & 33.36 & 189,651 & 26.36 \\
2013 & 694,957 & 288,894 & 41.57 & 184,965 & 26.62 & 221,098 & 31.81 \\
2012 & 641,622 & 276,732 & 43.13 & 175,513 & 27.35 & 189,377 & 29.52 \\
2011 & 575,757 & 285,230 & 49.54 & 154,643 & 26.86 & 135,884 & 23.60 \\
2010 & 477,573 & 242,130 & 50.70 & 121,797 & 25.50 & 113,643 & 23.80 \\
2009 & 478,235 & 208,988 & 43.70 & 136,876 & 28.62 & 132,371 & 27.68 \\
\hline
\end{tabular}

d. Source: West African Examinations Council (WAEC) Office, Yaba, Lagos (2018)

\section{Appendix B}

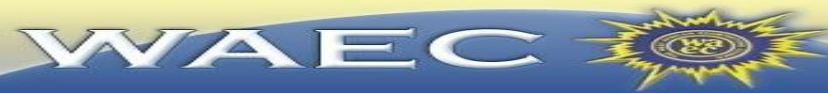

Chemistry Paper 2

(Essay), May/June 2017/2018

General Comments

Weakness/Remedies

Strength

\section{WEAKNESS/REMEDIES}

The weaknesses associated with candidates' performance include:

- lack of understanding of the demands of the question;

- non-adherence to rubrics;

- poor presentation/communication skills;

- spelling errors;

- inability to write chemical formulae accurately and balance chemical equation;

- inability to answer questions on organic chemistry such as alkanes, alkenes, alkanols, alkynes, ester, and alkanoic acids;

- poor knowledge of electrochemical cell and it related calculations;

- $\quad$ poor knowledge of redox reactions; alkanoic acids.

The following remedies were however suggested

- candidates should familiarize themselves with the required syllabus;

- teachers should emphasize on areas of the syllabus where candidates appear to be weak such as electro chemistry, Organic Chemistry, redox reaction and nuclear reaction;

- teachers should employ effective instructional methods; and experts/professionals should be employed to teach the subject;

- Teachers should be encouraged to attend/participate in marking coordination to update themselves.

e. Source: West African Examinations Council (WAEC) Office, Yaba, Lagos (2018) 